\title{
PENGARUH KEPUASAN KERJA DAN STRES KERJA TERHADAP INTENSI TURNOVER
}

\author{
M. Naffisya Kancana Gumilang \\ UIN Syarif Hidayatullah Jakarta \\ mohamad.naffisya@gmail.com
}

\author{
Akhmad Baidun \\ HIMPSI Provinsi Banten \\ akhmad.baidun@uinjkt.ac.id
}

\begin{abstract}
This study aimed to know the effect of job satisfaction and work stress toward turnover intention. Sample was used 196 employees of Bank Mandiri Syariah head office, usng nonprobability sampling technique. Data was analyzed using multiple regression analysis. Research indicated that there is a significant effect of job satisfaction and work stress toward employee turnover intention. Varians proportion from turnover intention that was explained by all predictors was $54,8 \%$. Hypotesis test result showed that payment, promotion, coworkers, nature of work and work stress behavior syndrome dimensions, had a significant effect toward turnover intention. Meanwhile, supervision, fringe benefit, contingent rewards, operating conditions, communication, physiological and psychological syndrome dimensions didn"t have effects toward turnover intention.
\end{abstract}

Keywords: Job Satisfaction, Work Stress, Turnover Intention

\begin{abstract}
Abstrak
Tujuan penelitian ini adalah untuk mengetahui pengaruh kepuasan kerja dan stres kerja terhadap intensi turnover. Sampel penelitian ini yaitu karyawan Bank Mandiri Syariah kantor pusat sebanyak 196 karyawan. Teknik sampling yang digunakan, yaitu dengan teknik non-probability sampling. Analisis data yang digunakan yaitu analisis regresi berganda. Hasil penelitian menunjukkan bahwa terdapat pengaruh yang signifikan kepuasan kerja dan stres kerja terhadap intensi turnover karyawan. Proporsi varians dari intensi turnover yang dijelaskan oleh seluruh variabel bebas yaitu sebesar 54.8. Hasil uji hipotesis menunjukkan bahwa dimensi gaji (pay), promosi (promotion), rekan kerja (co-workers), sifat pekerjaan (nature of work) dan gejala perilaku stres kerja memiliki pengaruh yang signifikan terhadap intensi turnover. Sedangkan dimensi supervisi (supervision), tunjangan (fringe benefit), penghargaan (contingent rewards), kondisi operasional (operating conditions), komunikasi (communication), gejala fisiologis, dan gejala psikologis tidak berpengaruh terhadap intensi turnover.
\end{abstract}

Kata Kunci: Kepuasan Kerja, Stres Kerja, Intensi Turnover

Diterima: 22 Agustus 2014 Direvisi: 21 September $2014 \quad$ Disetujui: 29 September 2014 


\section{PENDAHULUAN}

Sumber daya manusia dipandang sebagai aset yang penting untuk mencapai tujuan perusahaan. Manusia merupakan sumber daya yang dinamis dan selalu dibutuhkan dalam proses produksi barang maupun jasa. Selain itu, kualitas suatu perusahaan bergantung pada sumber daya manusia berkualitas yang dapat mengelola sumber daya lain di perusahaan secara optimal. Fenomena yang sering kali terjadi, yaitu terdapat penurunan kinerja yang dialami perusahaan karena berbagai kondisi dan perilaku karyawan. Salah satu perilaku yang menyebabkan masalah itu terjadi, yaitu intensi turnover (keinginan keluar) yang berakibat pada keputusan karyawan untuk keluar dari perusahaan secara voluntary turnover. Suatu penarikan diri secara sukarela (voluntary) atau tidak sukarela (unvoluntary) yang merupakan keputusan karyawan untuk meninggalkan organisasi diistilahkan sebagai turnover (Robbins, 2008).

Sementara itu, Kirn, Price, Mueller dan Watson (dalam Ahmad \& Riaz, 2011) menyatakan bahwa intensi turnover mengacu pada perkiraan peluang individu bahwa mereka akan meninggalkan organisasi pada suatu saat di masa depan. Sedangkan, intensi untuk menetap (intention to stay) mengacu pada sejauh mana rencana karyawan untuk melanjutkan keanggotaan dengan majikannya. Jadi, intensi turnover baru sebatas pada keinginan karyawan, belum sampai pada tahap realisasi perpindahan atau keluar dari tempat kerja (turnover) secara nyata. Meningkatnya intensi turnover telah menjadi masalah serius bagi banyak perusahaan. Angka perputaran karyawan (employee turnover) yang tinggi mengakibatkan bengkaknya biaya perekrutan, seleksi, dan pelatihan (Robbins \& Judge, 2008).

Fenomena turnover dialami oleh perbankan syariah di Indonesia. Menurut Edy Setiadi, Direktur Eksekutif Departemen Perbankan Syariah Bank Indonesia menyatakan bahwa pada tahun 2009, tingkat turnover di bank syariah hanya 5 persen, namun pada tahun 2010 meningkat menjadi 10 persen (Wiyanti, 2012). Terjadinya peningkatan turnover ini juga disinyalir karena minimnya SDM yang berkualitas dan berpengalaman, serta ketidakseimbangan pasokan SDM di bidang syariah, dimana permintaan di sesama bank syariah sangat tinggi, tapi pasokan SDM-nya masih kurang.

Ketersediaan SDM perbankan syariah di Indonesia tidak berbanding lurus dengan pertumbuhan industri perbankan syariah yang cukup pesat saat ini. Penyerapan sumber daya insani syariah sudah mencapai 5 kali lipat atau sekitar 400 persen sejak awal kemunculan perbankan syariah pada tahun 2000 (Wiyanti, 2012). Berdasarkan data Bank Indonesia (BI), total sumber daya insani (SDI) bank umum syariah serta unit usaha syariah mencapai 34,726 karyawan pada akhir Juni 2013, meningkat 9,972 karyawan atau $40 \%$ dari setahun sebelumnya (Banjarnahor, 2013). 
Kemudian, Ketua umum Asosiasi Bank Syariah Indonesia, Yuslam Fauzi menyatakan bahwa kebutuhan terhadap SDM perbankan syariah rata-rata 11.000 orang per tahun, tetapi institusi formal pendidikan di Indonesia hanya mampu memasok SDM ekonomi dan keuangan syariah sekitar 3.750 orang per tahun (Sanjaya, 2013). Atas dasar kurangnya SDM yang berpengalaman dibidang syariah, masih terjadi fenomena pembajakan karyawan antar bank syariah meskipun jumlah sudah berkurang (Banjarnahor, 2013). Oleh karena itu, kecenderungan meningkatnya turnover karyawan menjadi masalah penting bagi perusahaan. Hal ini dikarenakan ketidakseimbangan penawaran dan permintaan (supply and demand) SDM syariah yang berkualitas serta masih terjadinya pembajakan karyawan antara sesama bank syariah.

Kecenderungan meningkatnya turnover karyawan mengindikasikan bahwa ada faktor yang menyebabkan, seperti faktor pekerjaan maupun kondisi psikologis tiap individu. Berbicara kondisi psikologis, terdapat banyak faktor kondisi psikologis karyawan yang telah diteliti oleh beberapa penelitian tentang intensi turnover, beberapa diantaranya seperti faktor komitmen organisasional (Toly, 2001), faktor kepuasan kerja (Ahmad \& Riaz, 2011), faktor stres kerja (Manurung \& Ratnawati, 2012), dan faktor ketidakamanan kerja atau job insecurity (Hanafiah, 2014). Adapun, penelitian yang dilakukan oleh penulis akan menguji dan meneliti dua faktor kondisi psikologis yang menurut asumsi penulis masih menjadi faktor penting dalam mempengaruhi dan menjadi masalah pada intensi turnover karyawan. Kedua faktor tersebut, yaitu faktor kepuasan kerja dan stres kerja.

Faktor kepuasan karyawan terhadap pekerjaannya akan sangat berdampak pada perusahaan yang ditempatinya. Weitz (dalam Rhandawa, 2007) berpendapat bahwa ketidakpuasan kerja akan lebih prediktif untuk turnover. Perilaku yang dapat timbul dari ketidakpuasan dalam pekerjaan dapat bermacam-macam seperti, tidak masuk atau membolos pada saat kerja, pencurian terhadap aset perusahaan, datang terlambat, bahkan keluar dari pekerjaannya (Robbins, 2008). Tentu saja, perilaku tersebut dapat mengganggu efektivitas perusahaan termasuk produktivitas perusahaan.

Selanjutnya, pada beberapa penelitian, seperti penelitian yang dilakukan oleh Ucho, Mkavga, dan Onyishi (2012) menunjukkan bahwa kepuasan kerja berhubungan negatif dengan intensi turnover. Penelitian lain yang dilakukan juga oleh Suhanto (2009) mendapatkan hasil pengujian hipotesis yang membuktikan ada pengaruh negatif antara kepuasan kerja dengan intensi turnover.

Disamping faktor kepuasan kerja, ada faktor psikologis yang lain yang dapat menyebabkan karyawan ingin melakukan turnover, yaitu stres kerja. Sukmasari (2013) menulis di situs Detik.com tentang studi yang dilakukan UNI Global Union yang berbasis di Swiss menemukan lebih dari 80 persen perusahaan perbankan dan asuransi di 26 negara melaporkan 
buruknya kesehatan sebagai masalah yang dialami pegawainya selama dua tahun terakhir. Lebih dari setengah serikat pekerja di 16 negara di Eropa, empat di Asia, dan tiga di Afrika serta Amerika latin menyatakan bahwa anggotanya mengeluhkan kehidupan pribadi mereka yang berada dibawah tekanan cukup besar karena mereka memerangi krisis keuangan. Stres ditengarai sebagai masalah kesehatan utama yang dialami pegawai perbankan. Mereka khawatir kehilangan pekerjaan dan digantikan orang yang lebih muda, tidak bisa mencapai target penjualan, mendapat potongan gaji, dan harus menyelesaikan kerja tim dengan staf yang sedikit.

Fincham dan Rhodes (dalam Munandar, 2001) mengasumsikan bahwa stres dapat disimpulkan dari gejala dan tanda faal, perilaku, psikologikal dan somatik, merupakan hasil dari tidak atau kurang adanya kecocokan antara orang (dalam arti kepribadian, bakat, dan kecakapan) dan lingkungannya yang mengakibatkan ketidakmampuan dalam menghadapi berbagai tuntutan terhadap dirinya secara efektif. Selain itu, stres kerja dinyatakan sebagai suatu kondisi dinamik, dimana seseorang individu dihadapi dengan sebuah peluang, kendala atau tuntutan yang dikaitkan dengan apa yang sangat diinginkan dan hasilnya dipersepsikan sebagai sesuatu yang tidak pasti dan penting (Robbins, 2008).

Penelitian yang dilakukan oleh Suharso dan Christie (2009) didapatkan bahwa stres kerja dan affective well-being memiliki pengaruh yang signifikan terhadap intensi turnover, terutama pada stres kerja. Pengaruh stres kerja menandakan bahwa dalam kurun waktu yang lama dan dengan intensitas tinggi, stres dapat membuat individu tidak lagi nyaman dalam bekerja sehingga memutuskan untuk keluar dan menjauh dari sumber stres. Pada tingkat tertentu stres dapat merusak secara psikis dan fisik, sehingga stres pada pekerjaan dapat menimbulkan keinginan dari seseorang karyawan untuk berhenti bekerja (Suharso \& Christie, 2009).

Selain itu, penelitian lain yang dilakukan oleh Manurung dan Ratnawati (2012) juga mendapatkan hasil bahwa variabel stres kerja memiliki pengaruh positif dan signifikan terhadap intensi turnover karyawan. Pengaruh positif yang signifikan menunjukkan intensi turnover karyawan dari perusahaan ketika mereka merasa stres dengan pekerjaan (Shazad, Rehman, Shad, Gul, \& Khan, 2011).

Berdasarkan pertimbangan luasnya permasalahan yang diuraikan, antara lain masih sedikit penelitian tentang intensi turnover di bidang perbankan khususnya perbankan syariah, kecenderungan meningkatnya turnover karyawan setiap tahunnya ditambah dengan kebutuhan SDM berkualitas di sektor perbankan syariah yang masih langka, maka variabel intensi turnover yang disebabkan oleh dua faktor kondisi psikologis, yaitu kepuasan kerja dan stres kerja dalam berbagai hasil penelitian sebelumnya perlu dianalisis dan dikaji lebih lanjut. 


\section{Intensi Turnover}

Menurut Bluedorn (dalam Margono, Divinagracia, \& Nelloh, 2012), niat atau intensi turnover adalah sikap kecenderungan atau sejauh mana seorang karyawan memiliki kemungkinan untuk meninggalkan organisasi atau sukarela mengundurkan diri dari pekerjaannya. Sedangkan, Abelson (dalam Toly, 2001) menggambarkan intensi turnover sebagai pikiran untuk keluar, mencari pekerjaan di tempat lain, serta keinginan meninggalkan organisasi. Menurut Harninda (dalam Nasution, 2009), intensi turnover pada dasarnya adalah sama dengan keinginan berpindah karyawan dari satu tempat kerja ke tempat kerja lain. Pendapat tersebut menunjukkan bahwa intensi turnover adalah keinginan untuk berpindah, belum pada tahap realisasi yaitu melakukan perpindahan dari satu tempat kerja ke tempat kerja lainnya.

Narimawati (2007) menyatakan - Turnover Intention refers to the intention of an employee looking for alternative work in other places and has not been implemented in a actual behaviorll. Pernyataan ini menunjukkan bahwa keinginan berpindah mengacu pada maksud seorang karyawan mencari tempat pekerjaan alternatif lain dan belum diimplementasikan dalam perilaku nyata. Mobley, Griffeth, Hand, \& Meglino (dalam Lambert, 2006) menyatakan bahwa - Turnover intent is the cognitive process of thinking, planning, and desiring to leave a job.ll Dengan kata lain, intensi turnover ialah proses kognitif dalam berpikir, perencanaan, dan keinginan untuk meninggalkan suatu pekerjaan. Adapun maksud intensi turnover yang digunakan dalam penelitian ini ialah keinginan karyawan atau individu untuk keluar dari organisasi secara sukarela (voluntary) melalui proses berpikir, berencana dan berkeinginan, serta mencari alternatif pekerjaan lain. Faktor-faktor yang mempengaruhi intensi turnover antara lain : usia, lama kerja, tingkat pendidikan dan intelegensi, rasa ketertarikan terhadap perusahan, kepuasan kerja, status perkawinan, stres kerja, dan jenis kelamin.

\section{Kepuasan Kerja}

Menurut Siegel dan Lane (dalam Munandar, 2001) menerima batasan yang diberikan oleh Locke bahwa kepuasan kerja adalah "the appraisal of one"s job as attaining or allowing the attainment of one"s important job values, providing these values are congruent with or help fulfill one"s basic needs." Secara singkat, tenaga kerja yang puas dengan pekerjaannya merasa senang dengan pekerjaannya. Selain itu, kepuasan kerja biasa didefinisikan sebagai tingkat tentang pengaruh positif karyawan terhadap pekerjaan atau situasi pekerjaan (Locke; Spector dalam Jex, 2002). Sedangkan Howell dan Dipboye (dalam Munandar, 2001) memandang kepuasan kerja sebagai hasil keseluruhan dari derajat rasa suka atau tidak sukanya tenaga kerja terhadap berbagai aspek dari pekerjaan. Dengan kata lain kepuasan kerja mencerminkan sikap tenaga kerja terhadap pekerjaannya.

Robbins (2003) mendefinisikan kepuasan kerja sebagai suatu sikap umum terhadap pekerjaan seseorang, selisih antara banyak ganjaran yang 
diterima oleh seorang pekerja dan banyak ganjaran yang mereka yakini harus mereka terima. Kemudian Schultz dan Sydney (2006) mendefinisikan kepuasan kerja (job satisfaction) sebagai perasaan positif dan negatif kita serta sikap tentang pekerjaan kita. Sehingga, berdasarkan uraian beberapa definisi diatas, maka peneliti menyimpulkan definisi kepuasan kerja tersebut sebagai perasaan dan sikap positif seorang karyawan terhadap pekerjaan. Terdapat sembilan dimensi kepuasan kerja menurut Spector (1997) antara lain : gaji (pay), promosi (promotion), supervisi (supervision), tunjangan (fringe benefit), penghargaan (contingent rewards), kondisi operasional (operating conditions), rekan kerja (co-workers), sifat pekerjaan (nature of work), dan komunikasi (communication).

\section{Stres Kerja}

Dalam Suwarto (2010) mennyatakan stres dalam definisi kerja adalah suatu tanggapan adaptif, ditengahi oleh perbedaan individual dan/atau proses psikologis, yaitu konsekuensi dari setiap kegiatan (lingkungan), situasi, atau kejadian eksternal yang membebani tuntutan psikologis atau fisik yang berlebihan terhadap seseorang. Robbins (2008) dalam bukunya Perilaku Organisasi, stres adalah kondisi dinamik yang di dalamnya individu menghadapi peluang, kendala, atau tuntutan yang terkait dengan apa yang sangat diinginkan dan hasilnya dipersepsikan sebagai tidak pasti tetapi penting. Menurut Kahn (2006) stres ialah respon dari tubuh dan pikiran pada ketegangan atau beban bahwa ada tuntutan adaptasi, itu adalah setiap halangan yang mengganggu kesejahteraan mental dan fisik individu.

Stres adalah kondisi yang terjadi ketika transaksi orang-lingkungan memimpin individu untuk melihat perbedaan antara tuntutan situasi dan sumber daya (Sarafino dan Smith, 2011). Disisi lain, Seyle (1988 dalam Munandar, 2001) membedakan stres menjadi dua, yaitu distress (stres yang destruktif) dan eustress yang merupakan kekuatan yang positif (eustress mengandung suku awal yang dalam bahasa Yunani berarti _baik', seperti yang terdapat dalam kata euphoria). Berdasarkan uraian tersebut dapat menyimpulkan bahwa stres kerja yang dimaksud dalam penelitian ini ialah suatu tanggapan adaptif yang merupakan konsekuensi dari setiap kegiatan atau pekerjaan yang membebani tuntutan psikologis dan fisik secara berlebihan terhadap individu atau karyawan. Robbins (2008) membagi konsekuensi stres menjadi tiga kategori umum yang menjadi dimensi pada penelitian ini, yaitu gejala fisiologis, gejala psikologis, dan gejala perilaku. 


\section{Hipotesis Penelitian}

Hipotesis Mayor

$\mathrm{H}_{1}$ : Kepuasan Kerja dan Stres Kerja berpengaruh secara signifikan terhadap Intensi turnover.

\section{Hipotesis Minor}

$\mathrm{H}_{2}$ : Gaji (Pay) berpengaruh secara signifikan terhadap intensi turnover.

$\mathrm{H}_{3}$ : Promosi (Promotion) berpengaruh secara signifikan terhadap intensi turnover.

$\mathrm{H}_{4}$ : Supervisi (Supervision) berpengaruh secara signifikan terhadap intensi turnover.

$\mathrm{H}_{5}$ : Tunjangan (Fringe benefit) berpengaruh secara signifikan terhadap intensi turnover.

$\mathrm{H}_{6}$ : Penghargaan (Contingent Rewards) berpengaruh secara signifikan terhadap intensi turnover.

$\mathrm{H}_{7}$ : Kondisi operasional (Operating conditions) berpengaruh secara signifikan terhadap intensi turnover.

$\mathrm{H}_{8}$ : Rekan kerja (Co-workers) berpengaruh secara signifikan terhadap intensi turnover.

$\mathrm{H}_{9}$ : Sifat pekerjaan (Nature of work) berpengaruh secara signifikan terhadap intensi turnover.

$\mathrm{H}_{10}$ : Komunikasi (Communication) berpengaruh secara signifikan terhadap intensi turnover.

$\mathrm{H}_{11}$ : Gejala Fisiologis stres kerja berpengaruh secara signifikan terhadap intensi turnover.

$\mathrm{H}_{12}$ : Gejala Psikologis stres kerja berpengaruh secara signifikan terhadap intensi turnover.

$\mathrm{H}_{13}$ : Gejala Perilaku stres kerja berpengaruh secara signifikan terhadap intensi turnover.

\section{METODE}

Penelitian ini menggunakan pendekatan kuantitatif dengan analisis multiple regression. Peneliti menentukan sampel berdasarkan individu yang sesuai dengan kriteria yang telah ditentukan oleh peneliti. yaitu mencakup jabatan di tingkat staf dan memiliki masa kerja minimal satu tahun. Sampel dalam penelitian ini ditetapkan sebanyak 196 orang karyawan Bank Mandiri Syariah kantor pusat yang ditentukan dengan teknik non-probability sampling.. Peneliti menganggap selama satu tahun bekerja, karyawan sudah mengenal dan merasakan situasi organisasi di tempat bekerja.

Peneliti mengukur variabel Intensi turnover menggunakan 13 item favourable dan unfavourable yang berasal dari tiga alat ukur intensi turnover. Pertama, alat ukur intensi turnover yang didesain oleh Crossley, Grauer, 
Lin, dan Stanton (dalam Crossley, Bennet, Jex, \& Burnfield, 2007) sebanyak 5 item. Kedua, alat ukur intensi turnover yang digunakan oleh Kelloway, Gottlieb, and Barham (dalam Bushra, 2012) sebanyak 4 item. Ketiga, alat ukur intensi turnover yang dikembangkan oleh Hom dan Griffeth (dalam Dawley, Houghton, \& Bucklew, 2010) sebanyak 2 item. Sedangkan, alat ukur yang dibuat oleh peneliti sendiri berjumlah 2 item. Keseluruhan item tersebut dikelompokkan ke dalam tiga dimensi berdasarkan proses intensi turnover menurut Mobley, Horner, dan Hollingworth (1978 dalam Munandar, 2001), yaitu proses berpikir untuk berhenti dari pekerjaan, proses berniat mencari pekerjaan lain, dan berniat untuk meninggalkan pekerjaan. Instrumen ini menggunakan skala model Likert. Terdapat 12 item yang valid setelah dilakukan uji validitas.

Peneliti mengukur variabel kepuasan kerja menggunakan adaptasi alat ukur kepuasan kerja yang digunakan peneliti mengacu pada alat ukur JJS (Job Satisfaction Survey) yang dikembangkan oleh Spector (1985) yang berisi 36 item favourable dan unfavourable. Terdapat 29 item yang valid setelah dilakukan uji validitas.

Peneliti mengukur variabel stres kerja menggunakan alat ukur yang dibuat sendiri oleh peneliti sebanyak 28 item berdasarkan tiga dimensi yang mengacu pada kategori konsekuensi stres menurut Robbins (2008), yaitu gejala fisiologis, gejala psikologis, dan gejala perilaku stres kerja. Terdapat 20 item yang valid setelah dilakukan uji validitas.

\section{HASIL}

Dari hasil analisis multiple regression diperoleh bahwa perolehan $\mathrm{R}$ square sebesar 0,548 atau $54,8 \%$. Artinya proporsi varians dari intensi turnover yang dijelaskan oleh semua independent variable sebesar 54,8\%, sementara $45,2 \%$ sisanya dipengaruhi oleh variabel lain di luar penelitian ini.

Tabel 1

Model Summary $R$

\begin{tabular}{llccc}
\hline Model & R & R Square & Adjusted R Square & $\begin{array}{c}\text { Std. Error of the } \\
\text { Estimate }\end{array}$ \\
\hline 1 & $.740^{\mathrm{a}}$ & .548 & .518 & 6.79815 \\
\hline a. & Predictors: (Constant), Gejala Perilaku, Kondisi Operasional (Operating \\
conditions), Penghargaan (Contingent Reward), Promosi (Promotion), Supervisi \\
(Supervision), Gejala Fisiologis, Komunikasi (Communication), Rekan Kerja \\
(Co-workers), Tunjangan (Fringe Benefit), Sifat Pekerjaan (Nature of Work), \\
Gejala Psikologis, Gaji (Pay)
\end{tabular}

Adapun, hasil uji $\mathrm{F}$ dapat dilihat pada tabel 2. Jika melihat kolom ke 6 dari kiri diketahui bahwa $(\mathrm{p}<0,05)$, maka hipotesis nihil yang menyatakan tidak ada pengaruh yang signifikan dari seluruh independent variable terhadap 
intensi turnover di tolak. Artinya, ada pengaruh yang signifikan dari gaji (pay), promosi (promotion), supervisi (supervision), tunjangan (fringe benefit), penghargaan (contingent rewards), kondisi operasional (operating conditions), rekan kerja (co-workers), sifat pekerjaan (nature of work), komunikasi (communication), gejala fisiologis, gejala psikologis, dan gejala perilaku terhadap intensi turnover.

\section{Tabel 2}

Anova Pengaruh Seluruh IV Terhadap DV

\begin{tabular}{llrrrrr}
\hline & Model & Sum of Squares & \multicolumn{1}{c}{ df } & Mean Square & F & \multicolumn{1}{c}{ Sig. } \\
\hline 1 & Regression & 10249.620 & 12 & 854.135 & 18.482 & $.000^{\mathrm{a}}$ \\
& Residual & 8457.312 & 183 & 46.215 & & \\
& Total & 18706.931 & 195 & & & \\
\hline
\end{tabular}

Peneliti melakukan uji hipotesis (minor) untuk melihat koefisien regresi setiap independent variable. Jika nilai $t>1,96$ maka koefisien regresi tersebut signifikan yang berarti bahwa IV tersebut memiliki dampak yang signifikan terhadap intensi turnover. Adapun koefisien regresi masing-masing IV dapat dilihat pada tabel 3.

Untuk melihat signifikan atau tidaknya suatu koefisien yang dihasilkan, maka cukup dengan melihat nilai sig pada kolom yang paling kanan, jika $p<0,05$, maka koefisien regresi yang dihasilkan signifikan pengaruhnya terhadap intensi turnover dan sebaliknya. Dari hasil tabel 3 dapat dilihat bahwa hanya koefisien regresi gaji (pay), promosi (promotion), rekan kerja (co-workers), sifat pekerjaan (nature of work) dan gejala perilaku stres kerja yang berpengaruh atau signifikan terhadap intensi turnover, sedangkan variabel lain tidak signifikan. 
Tabel 3

Koefisien Regresi ${ }^{a}$

\begin{tabular}{|c|c|c|c|c|c|}
\hline \multirow[t]{2}{*}{ Model } & \multicolumn{2}{|c|}{$\begin{array}{c}\text { Unstandardized } \\
\text { Coefficients } \\
\end{array}$} & \multirow{2}{*}{$\begin{array}{c}\begin{array}{c}\text { Standardized } \\
\text { Coefficients }\end{array} \\
\text { Beta } \\
\end{array}$} & \multirow[t]{2}{*}{$t$} & \multirow[t]{2}{*}{ Sig. } \\
\hline & $B$ & Std. Error & & & \\
\hline 1 (Constant) & 73.511 & 4.436 & & 7.433 & .000 \\
\hline Gaji (Pay) & -.258 & .124 & -.247 & -2.083 & $.039^{*}$ \\
\hline Promosi (Promotion) & -.414 & .084 & -.373 & -4.926 & $.000^{*}$ \\
\hline Supervisi (Supervision) & -.001 & .085 & -.001 & -.017 & .987 \\
\hline $\begin{array}{l}\text { Tunjangan (Fringe Benefit) } \\
\text { Penghargaan }\end{array}$ & .105 & .111 & .098 & .946 & .345 \\
\hline $\begin{array}{l}\text { (Contingent Rewards) } \\
\text { Kondisi Operasional }\end{array}$ & .068 & .088 & .058 & .768 & .443 \\
\hline (Operating Conditions) & -.170 & .086 & -.152 & -1.971 & .050 \\
\hline Rekan Kerja (Co-workers) & .205 & .073 & .210 & 2.798 & $.006^{*}$ \\
\hline Sifat Pekerjaan (Nature Of Work) & -.295 & .083 & -.273 & -3.551 & $.000^{*}$ \\
\hline Komunikasi (Communication) & .035 & .094 & .029 & .373 & .710 \\
\hline Gejala Fisiologis & -.091 & 0.85 & -.086 & -1.070 & .286 \\
\hline Gejala Psikologis & .153 & .092 & .144 & 1.656 & .099 \\
\hline Gejala Perilaku & .194 & .063 & .191 & 3.049 & $.003^{*}$ \\
\hline
\end{tabular}

a. Dependent Variable: Intensi Turnover

Berdasarkan koefisien regresi di atas dapat dijelaskan persamaan regresi sebagai berikut: ( ${ }^{*}$ signifikan)

Intensi turnover $=73.511-0.247^{*}$ gaji (pay) $-0.373^{*}$ promosi (promotion) 0.001 supervisi (supervision) +0.098 tunjangan (fringe benefit) +0.058 penghargaan (contingent rewards) - 0.152 kondisi operasional (operating conditions) $+0.210^{*}$ rekan kerja (co-workers) $-0.273^{*}$ sifat pekerjaan (nature of work $)+0.373$ komunikasi (communication) -0.086 gejala fisiologis +0.144 gejala psikologis $+0.191^{*}$ gejala perilaku $+e$

Berdasarkan tabel 3 maka dapat diartikan dari 12 hipotesis minor terdapat 6 variabel yang signifikan. Nilai koefisien regresi yang diperoleh masing-masing IV akan dijelaskan di bawah ini.

1. Variabel Gaji (Pay) diperoleh nilai koefisien regresi sebesar -0.258 dengan signifikansi $0.039(p<0,05)$, artinya variabel gaji (pay) berpengaruh secara signifikan terhadap intensi turnover. Artinya semakin tinggi kepuasan seorang karyawan pada dimensi gaji, maka semakin rendah intensi turnover karyawan tersebut.

2. Variabel Promosi (Promotion) diperoleh nilai koefisien regresi sebesar 0.414 dengan signifikansi $0.000(\mathrm{p}<0,05)$, artinya variabel promosi (promotion) berpengaruh secara signifikan terhadap intensi turnover. Artinya semakin tinggi kepuasan seorang karyawan pada dimensi promosi, maka semakin rendah intensi turnover karyawan tersebut. 
3. Variabel Supervisi (Supervision) diperoleh nilai koefisien regresi sebesar 0.001 dengan signifikansi 0.987 ( $p>0,05$ ), artinya variabel supervisi (supervision) tidak berpengaruh secara signifikan terhadap intensi turnover.

4. Variabel Tunjangan (Fringe Benefit) diperoleh nilai koefisien regresi sebesar 0.105 dengan signifikansi $0.345(\mathrm{p}>0,05)$, artinya variabel tunjangan (fringe benefit) tidak berpengaruh secara signifikan terhadap intensi turnover.

5. Variabel Penghargaan (Contingent Rewards) diperoleh nilai koesfisien regresi sebesar 0.068 dengan signifikansi 0.443 ( $p>0,05)$, artinya variabel penghargaan (contingent rewards) tidak berpengaruh secara signifikan terhadap intensi turnover.

6. Variabel Kondisi Operasional (Operating Conditions) diperoleh nilai koefisien regresi sebesar -0.170 dengan signifikansi $0.050 \quad(p>0,05)$, artinya variabel kondisi operasional (operating conditions) tidak berpengaruh secara signifikan terhadap intensi turnover.

7. Variabel Rekan Kerja (Co-workers) diperoleh nilai koefisien regresi sebesar 0.205 dengan signifikansi $0.006(p<0,05)$, artinya variabel rekan kerja (coworkers) berpengaruh secara signifikan terhadap intensi turnover. Artinya semakin tinggi kepuasan seorang karyawan pada dimensi rekan kerja, maka semakin tinggi intensi turnover karyawan.

8. Variabel Sifat Pekerjaan (Nature Of Work) diperoleh nilai koefisien regresi sebesar -0.295 dengan signifikansi $0.000 \quad(\mathrm{p}<0,05)$, variabel sifat pekerjaan (nature of work) berpengaruh secara signifikan terhadap intensi turnover. Artinya semakin tinggi kepuasan seorang karyawan pada dimensi sifat pekerjaan, maka semakin rendah intensi turnover karyawan.

9. Variabel Komunikasi (Communication) diperoleh nilai koesfisien regresi sebesar 0.035 dengan signifikansi $0.710(\mathrm{p}>0,05)$, artinya variabel komunikasi (communication) tidak berpengaruh secara signifikan terhadap intensi turnover.

10. Variabel Gejala Fisiologis diperoleh nilai koesfisien regresi sebesar -0.091 dengan signifikansi 0.286 ( $>>0,05)$, artinya variabel gejala fisiologis stres kerja tidak berpengaruh secara signifikan terhadap intensi turnover.

11. Variabel Gejala Psikologis diperoleh nilai koesfisien regresi sebesar 0.153 dengan signifikansi 0.099 ( $p>0,05)$, artinya variabel gejala psikologis stres kerja tidak berpengaruh secara signifikan terhadap intensi turnover.

12. Variabel Gejala Perilaku diperoleh nilai koefisien regresi sebesar 0.194 dengan signifikansi $0.003(p<0,05)$, variabel gejala perilaku stres kerja berpengaruh secara signifikan terhadap intensi turnover. Artinya semakin tinggi gejala perilaku stres kerja seorang karyawan, maka semakin tinggi pula intensi turnover karyawan tersebut. 
Tabel 4

Proporsi Varians Masing-Masing Independent Variable

\begin{tabular}{clcc}
\hline & \multicolumn{3}{c}{ Change Statistics } \\
\cline { 2 - 4 } Model & $\begin{array}{c}\text { R Square } \\
\text { Change }\end{array}$ & Sig. F Change \\
\hline 1 & Gaji (Pay) & .323 & $.000^{*}$ \\
2 & Promosi (Promotion) & .097 & $.000^{*}$ \\
3 & Supervisi (Supervision) & .003 & .349 \\
4 & Tunjangan (Fringe Benefit) & .000 & .686 \\
5 & Penghargaan (Contingent Rewards) & .009 & .091 \\
6 & Kondisi Operasional (Operating Conditions) & .010 & .072 \\
7 & Rekan kerja (Co-Workers) & .016 & $.021^{*}$ \\
8 & Sifat Pekerjaan (Nature Of Work) & .049 & $.000^{*}$ \\
9 & Komuniasi (Communication) & .007 & .098 \\
10 & Gejala Fisiologis & .000 & .686 \\
11 & Gejala Psikologis & .011 & $.038^{*}$ \\
12 & Gejala Perilaku & .023 & $.003^{*}$ \\
\hline
\end{tabular}

*signifikan

Berdasarkan tabel 4 maka dapat disusun urutan IV yang secara signifikan memberikan sumbangan dalam varian DV dari yang terkecil hingga terbesar. Variabel dengan sumbangan terkecil adalah variabel gejala psikologis dengan $R^{2}$ change sebesar $1,1 \%$, kemudian variabel rekan kerja (coworkers) dengan $R^{2}$ change sebesar $1.6 \%$, disusul oleh variabel gejala perilaku dengan $R^{2}$ change 2,3\%, lalu variabel sifat pekerjaan (nature of work) dengan $R^{2}$ change sebesar 4,9\%, kemudian variabel promosi (promotion) dengan $R^{2}$ change sebesar 9,7\%, dan terbesar adalah variabel gaji (pay) dengan $R^{2}$ change sebesar $32,3 \%$.

\section{DISKUSI}

Hasil penelitian ini menunjukkan bahwa keseluruhan independent variable, yaitu kepuasan kerja dan stres kerja secara signifikan berpengaruh terhadap intensi turnover karyawan. Hal tersebut ditunjukkan dari hasil uji $\mathrm{F}$ yang menguji seluruh independent variable terhadap dependent variable.

Berdasarkan hasil uji hipotesis, variabel kepuasan kerja berpengaruh secara signifikan terhadap intensi turnover karyawan. Hal ini mendukung hasil penelitian sebelumnya yang dilakukan oleh Hanafiah (2014) bahwa kepuasan kerja berpengaruh secara signifikan terhadap intensi pindah kerja (intensi turnover). Sejalan dengan pendapat Robbins (2008) yang menyatakan bahwa kepuasan kerja berkorelasi dengan pengunduran diri (turnover).

Robbins juga menyatakan bahwa kepuasan kerja lebih penting dalam mempengaruhi karyawan yang berkinerja buruk untuk bertahan daripada karyawan yang berkinerja baik. Hal tersebut dapat terjadi bila perusahaan 
tidak melakukan upaya untuk memperbaiki tingkat kepuasan kerja karyawan. Dengan tingkat kepuasan kerja yang tinggi, karyawan yang berkinerja baik berkemungkinan lebih besar untuk bertahan pada organisasi tersebut karena menerima pengakuan, pujian, dan hadiah lain yang memberi mereka lebih banyak alasan untuk bertahan. Sebaliknya, apabila tingkat kepuasan kerja rendah, maka muncul ketidakpuasan kerja karyawan yang berdampak pada perusahaan, yaitu perilaku yang mengarah untuk meninggalkan organisasi (Robbins, 2003). Kemudian, penelitian yang dilakukan oleh Randhawa (2007) juga menunjukkan hasil yang sama bahwa kepuasan kerja memiliki korelasi yang signifikan dan negatif terhadap intensi turnover. Artinya apabila semakin tinggi kepuasan kerja yang dimiliki individu atau karyawan, maka semakin rendah intensi turnover karyawan tersebut.

Dilihat dari pengaruh perdimensi variabel kepuasan kerja, terdapat empat dimensi kepuasan kerja yang berpengaruh secara signifikan, yaitu gaji (pay), promosi (promotion), rekan kerja (co-workers), dan sifat pekerjaan (nature of work). Pada dimensi gaji (pay) secara negatif dan signifikan mempengaruhi intensi turnover serta memberikan sumbangan pengaruh terbesar dalam varians intensi turnover sebesar 32.3\%.

Kemudian, melihat hasil penelitian menunjukkan terdapat pengaruh secara signifikan stres kerja terhadap intensi turnover karyawan. Mengacu pada konsekuensi stres menurut Robbins (2008), pengaruh stres pada organisasi salah satunya ialah perilaku keluarnya karyawan dari perusahaan/organisasi. Kemudian, hasil penelitian tersebut mendukung penelitian yang telah dilakukan oleh Manurung dan Ratnawati (2012) yang mendapatkan hasil bahwa variabel stres kerja memiliki pengaruh positif dan signifikan terhadap intensi turnover karyawan. Penelitian yang dilakukan oleh Qureshi et.al (2013) juga mendapatkan hasil yang sama bahwa stres kerja secara positif dan signifikan berkorelasi dengan intensi turnover. Hal ini berarti semakin tinggi tingkat stres kerja yang dialami oleh karyawan, maka semakin tinggi pula tingkat intensi turnover karyawan.

Tingkat stres yang tinggi dapat diatasi dengan mengurangi stressor yang menjadi penyebab stres kerja karyawan. Jika perusahaan ingin mempertahankan modal intelektual karyawan atau sumber daya manusia berkualitas, maka perusahaan harus mengurangi penyebab stres kerja (stressor) yang mengarah pada pergantian atau turnover karyawan (Qureshi, et.al., 2013). Jika dilihat hasil perdimensi variabel stres kerja berdasarkan konsekuensi stres kerja, antara lain gejala fisiologis stres kerja, gejala psikologis stres kerja, dan gejala perilaku stres kerja, maka hanya satu dimensi yang secara signifikan dan positif berpengaruh terhadap intensi turnover, yaitu gejala perilaku stres kerja

Adapun keterbatasan dan koefisien regresi yang tidak signifikan dalam penelitian ini dikarenakan beberapa hal yang merupakan asumsi peneliti antara lain: (1) Meski belum di uji secara statistik, terdapat 
kecenderungan sampel untuk menjawab secara normatif sehingga data yang diperoleh cenderung kurang representatif. (2) Minimnya penelitian terdahulu yang menghubungkan antara variabel kepuasan kerja dan variabel stres kerja berdasarkan teori dan dimensi yang peneliti gunakan terhadap intensi turnover menyebabkan penelitian ini terbatas secara kajian literatur.

(3) adanya individual difference setiap karyawan sehingga memiliki penilaian yang berbeda terhadap variabel kepuasan kerja dan variabel stres kerja. (4) pengukuran terhadap variabel terikat, yaitu intensi turnover menggunakan penggabungan dari tiga alat ukur yang telah dikembangkan oleh peneliti lain dan satu alat ukur yang dibuat oleh peneliti sendiri. Penggabungan keempat alat ukur tersebut bertujuan untuk dapat melengkapi pengukuran berdasarkan tiga dimensi intensi turnover yang peneliti gunakan. Akan tetapi, penggunaan penggabungan keempat alat ukur tersebut menjadikan variabel terikat tersebut berkonsep multidimensional. Padahal, yang dimaksud dalam penelitian ini merupakan variabel yang unidimensional, hal ini dikarenakan terbatasnya alat ukur untuk menyesuaikan dengan ketiga dimensi intensi turnover yang peneliti gunakan.

Berdasarkan kategorisasi hasil penelitian ini, mayoritas karyawan memiliki intensi turnover pada level sedang, sedangkan jumlah karyawan yang memiliki intensi turnover dengan level tinggi mencapai $10.2 \%$ dari total sampel atau lebih rendah dari karyawan yang memiliki intensi turnover yang rendah (14.8\%). Artinya, sebagian besar karyawan memiliki intensi turnover sedang dan cenderung rendah.

Berikut ini saran yang dapat penelitia berikan terkait penelitian ini:

1. Berdasarkan hasil analisis regresi, sumbangan efektif dari hasil penelitian pada variabel kepuasan kerja dan stres kerja terhadap intensi turnover menunjukkan pengaruh secara keseluruhan sebesar $54.8 \%$ dan selebihnya dipengaruhi oleh variabel lain. Untuk penelitian selanjutnya disarankan agar melakukan penelitian untuk menguji faktor lain yang mempengaruhi intensi turnover seperti psychological climate (Sahin, 2011), organizational culture (Kumar, Ramendran, \& Yacob, 2012), atau work life conflict (Noor \& Maad, 2008). Dengan mempertimbangkan variabel tersebut, diharapkan penelitian selanjutnya akan lebih menyempurnakan hasil dalam penelitian ini.

2. Untuk penelitian selanjutnya disarankan untuk menggunakan alat ukur yang berbeda dan lebih baru dari alat ukur yang digunakan pada penelitian ini, terutama pada alat ukur variabel stres kerja. Hal ini dikarenakan terdapat cukup banyak item yang tidak valid atau di drop pada dimensi gejala perilaku. Selain itu, penggunaan alat ukur yang berbeda agar mendapatkan perbandingan antara alat ukur yang digunakan penelitian ini dengan alat ukur pada penelitian selanjutnya.

3. Berdasarkan hasil uji validitas konstruk pada variabel stres kerja, ditemukan bahwa 8 item dari 28 item yang digunakan penelitian ini tidak valid $(\mathrm{t}<1.96$ dan factor loading $<0.55)$, terutama pada dimensi 
gejala perilaku variabel stres kerja ditemukan 6 dari 10 item yang tidak valid. Peneliti berasumsi hal ini disebabkan oleh penggunaan kalimat yang kurang baik sehingga menyebabkan kesalahan dalam memperoleh data. Oleh karena itu, peneliti menyarankan agar penelitian selanjutnya melakukan pilot study pada responden yang akan diteliti dan menganalisa dengan bertanya langsung apakah kalimat yang digunakan dalam alat ukur tersebut mudah dipahami atau tidak.

4. Pada penelitian selanjutnya, pengujian pengaruh variabel stres kerja dapat menggunakan teori dan indikator stres kerja yang lebih baru dan kompleks, karena penggunaan teori dan indikator yang digunakan pada penelitian ini dirasakan masih belum komplek dalam mengukur stres kerja karyawan. Hal tersebut agar pengukuran terhadap variabel stres kerja dapat lebih mendalam dan terperinci.

5. Mempertimbangkan kesimpulan penelitian ini yang menunjukkan bahwa kepuasan kerja dan stres kerja berpengaruh secara signifikan terhadap intensi turnover karyawan. Kemudian, hasil penelitian menunjukkan bahwa tingkat intensi turnover karyawan pada kategori sedang merupakan yang terbanyak, yaitu sebanyak $75 \%$ dari total responden atau 147 karyawan. Oleh karena itu, organisasi atau perusahaan terutama Bank Mandiri Syariah kantor pusat disarankan agar dapat meningkatkan dan menjaga kepuasan kerja dengan semaksimal mungkin serta menurunkan tingkat stres (distress) yang dialami karyawan dan mengurangi sumber stres (stressor) hingga tingkat terendah untuk menurunkan intensi turnover. Hal tersebut dapat dilakukan dengan cara evaluasi faktor kepuasan dan sumber stres (stressor) kerja pada karyawan.

6. Berdasarkan hasil penelitian, variabel kepuasan kerja pada dimensi gaji (pay) merupakan dimensi yang memiliki kontribusi varians terbesar terhadap intensi turnover. Oleh karena itu, peneliti menyarankan agar perusahaan melakukan upaya untuk meningkatkan kepuasan tersebut dengan memberikan gaji yang kompetitif kepada para karyawan untuk menekan tingkat intensi turnover karyawan pada level terendah.

\section{DAFTAR PUSTAKA}

Ahmad, T., \& Riaz, A. (2011). Factors Affecting Turn-Over Intentions of Doctors in Public Sector Medical Colleges and Hospitals. Interdisciplinary Journal of Research in Business, November 1(10), 57-66

Banjarnahor, D. (2013). Perbankan Syariah Tambah 10.000 Karyawan. Diunduh pada tanggal 12 Desember 2013 dari http://www.bisnis.com/articles/regulasi-perbankan-jadi-faktorpenghambat-utama 
Bushra, A. (2012). Job Satisfaction and Women's Turnover Intentions in Pakistan's Public Universities. The Lahore Journal of Business, 1(1), 5977

Crossley, C., Bennet, R.J., Jex, S.M., Burnfield, J.L. (2007). Development of a global measure of job embeddedness and integration into a traditional model of voluntary turnover. Journal of Applied Psychology, 92(4), 1031-1042. DOI: 10.1037/0021-9010.92.4.1031

Dawley, D., Houghton, J.D., Bucklew, N.S. (2010). Perceived Organizational Support and Turnover Intention: The Mediating Effects of Personal Sacrifice and Job Fit. The Journal of Social Psychology, 150(3), 238-257

Hanafiah, M. (2014). Pengaruh Kepuasan Kerja Dan Ketidakamanan Kerja (Job Insecurity) dengan Intensi Pindah Kerja (Turnover) pada Karyawan PT. BUMA Desa Suaran Kecamatan Sambaliung Kabupaten Berau. Ejournal Psikologi, 1(3), 303-312

Robbins, S. P., \& Judge, T.A. (2008). Perilaku Organisasi (Organizational behavior).edisi 12. Jakarta: Salemba Empat

Sahin, F. (2011). Affective Commitment as a Mediator of the Relationship Between Psychological Climate and Turnover Intention. World Applied Sciences Journal, 14(4), 523-530

Sarafino, E.P., \& Smith, T.W. (2011). Health Psychology: Biopsychosocial Interactions, seventh edition. USA : John Wiley \& Sons, Inc.

Schultz, D.P., \& Schultz, S.E. (2006). Psychology \& Work Today : Ninth edition. Pearson Education International

Shahzad, K., Rehman, U., Shad, I., Gul, A., \& Khan, M.A. (2011). WorkLife Policies anda Job Stress as Determinants of Turnover Intentions of Customer Service Representatives in Pakistan. European Journal of Social Sciences, 19(3)

Soeharso, S.P \& Christie, Y. (2009). Pengaruh Iklim Psikologis Authentizotic, Stres Kerja dan Kebahagiaan Karyawan terhadap Intensi Turnover. Mindset, Desember, 1(1). 27-44

Spector, P.E. (1997). Job Satisfaction : Application, Assessment, Causes anda Consequences. United States of America: Sage Publictions, Inc.

Suhanto, E. (2009). Pengaruh Stres Kerja dan Iklim Organisasi terhadap Turnover Intention Dengan Kepuasan Kerja Sebagai Variabel Intervening, Studi di Bank Internasional Indonesia. Tesis Program Studi Magister Manajemen Program Pasca Sarjana Universitas Diponegoro

Sukmasari, R.N. (2013). Studi Baru Sebut Pegawai Perbankan Lebih Rentan Stres karena Tertekan. Diunduh tanggal 18 November 2013 dari

http://health.detik.com/read/2013/10/16/151622/2387114/763/st udi-baru-sebut-pegawai-perbankan-lebih-rentan-stres-karena-tertekan

Suwarto, FX. (2010). Perilaku Keorganisasian : Buku Panduan Mahasiswa. Yogyakarta : Penerbit Universitas Atma Jaya Yogyakarta 
Toly, A.A. (2001). Analisis Faktor-Faktor Yang Mempengaruhi Turnover Intentions Pada Staf kantor Akuntan Publik. Jurnal Akutansi \& Keuangan, 3(2)

Ucho, A., Mkavga, T., Onyishi, I.E. (2012). Job Satisfaction, Gender, Tenure, and Turnover Intentions among Civil Servants in Benue State. Interdisciplinary Journal Of Contemporary Research In Business, $3(11)$

Westlund, S.G., \& Hannon, J.C. (2008). Retaining Talent: Assessing Jobb Satisfaction Facets Most Significantly Related To Software Developer Turnover Intentions. Journal of Information Technology Management, 19(4) 
